\title{
Fútbol, modelos jurídicos y mercado: el dilema de los clubes en Sudamérica
}

Football, Legal Models and Market: The Dilemma of Clubs in South America Football, modèles juridiques et marché: le dilemme des clubs en Amérique du Sud

\section{Verónica Moreira}

\section{(2) OpenEdition}

\section{Journals}

Edición electrónica

URL: http://journals.openedition.org/rccs/7327

DOI: $10.4000 /$ rccs.7327

ISSN: 2182-7435

Editor

Centro de Estudos Sociais da Universidade de Coimbra

\section{Edición impresa}

Fecha de publicación: 1 septiembre 2018

Paginación: 135-154

ISSN: 0254-1106

\section{Referencia electrónica}

Verónica Moreira, « Fútbol, modelos jurídicos y mercado: el dilema de los clubes en Sudamérica », Revista Crítica de Ciências Sociais [En línea], 116 | 2018, Publicado el 31 julio 2018, consultado el 11 septiembre 2020. URL : http://journals.openedition.org/rccs/7327 ; DOI : https://doi.org/10.4000/ rccs. 7327

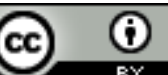




\section{VERÓNICA MOREIRA}

\section{Fútbol, modelos jurídicos y mercado: el dilema de los clubes en Sudamérica}

El trabajo relaciona tres dimensiones que articulan las discusiones sobre el fútbol en América del Sur: hinchas, mercado y política interna. En primer lugar se presenta el debate desencadenado en torno al formato legal de las instituciones. Resulta necesario hacer esta primera escala sobre los clubes y sus modelos legales, para introducir de inmediato las formas de participación y organización que los actores involucrados encuentran en ésta área. Como las transformaciones económicas y políticas de los clubes no ocurren aisladamente, la segunda parte del trabajo explica las medidas que fueron incorporadas en el campo deportivo como parte de un proceso global de mercantilización. La tercera parte se centra en cómo los socios e hinchas expresan su descontento frente a las transformaciones estructurales y decisiones políticas tomadas por los dirigentes de los clubes.

Palabras clave: América del Sur; fútbol; lucro; mercantilización; sociedades anonimas.

Palavras-chave: América do Sul; futebol; lucro; mercantilização; sociedades anónimas.

\section{Introducción}

No es una novedad que el fútbol se ha convertido en objeto privilegiado de las Ciencias Sociales. En Sudamérica, la inauguración del campo de los estudios sociales del deporte se dio a mediados de la década de los ochenta del siglo pasado con la publicación de dos textos emblemáticos: Universo do Futebol: esporte e sociedade brasileira ${ }^{1}$ de Roberto DaMatta (1982) y Fútbol y ethos del argentino Eduardo Archetti (1984). A lo largo de estos treinta años se han llevado a cabo diversas investigaciones sobre el fenómeno futbolístico. Entre los temas más estudiados destacan: la comprensión de las distintas manifestaciones de la violencia, el rol del mercado y los medios de comunicación, las relaciones con la política tradicional y la construcción de las identidades nacionales,

\footnotetext{
${ }^{1}$ En la compilación participó Simoni Lahud Guedes, referente del campo de estudios sobre deporte de la región. El lector interesado en el desarrollo del campo en Latinoamérica, puede consultar la obra de otro referente: Alabarces (2012).
} 
étnicas y de género. Por un lado, tales reflexiones han tenido como objetivos comprender la lógica interna, propia y específica del hecho deportivo en sí, y por otro, vincular dicha especificidad con los procesos sociales, históricos y culturales más amplios.

En el marco de dicho recorrido, el presente trabajo tiene como objetivo analizar un aspecto que ha cobrado visibilidad en los últimos años tanto en la agenda pública como en los centros de estudios académicos, a saber: la relación entre el modelo jurídico de los clubes de fútbol y el inexorable proceso de mercantilización de este deporte. Esta pregunta de investigación se une a la tradicional línea de abordaje acerca de cuál es el margen de acción de los socios e hinchas vinculados a entidades deportivas, en un contexto de privatización y avance del neoliberalismo. Si bien el análisis se apoya particularmente en el caso argentino, que hemos estudiado en profundidad, también cuenta con datos extraídos de Brasil y otros países de Sudamérica.

Los datos que funcionan como evidencia del presente análisis, surgieron del trabajo realizado en distintas instituciones deportivas argentinas. Una primera etapa tuvo lugar en 2010 en el Club Atlético Independiente, el Racing Club y el Arsenal Fútbol Club, ubicados en el Partido de Avellaneda, al sur de la Ciudad de Buenos Aires. Las técnicas de investigación implementadas fueron la observación participante y la entrevista en profundidad. La segunda etapa, que tuvo lugar en 2013, implicó crear una base de datos sobre el resto de las instituciones futbolísticas de la primera división de fútbol (20 equipos en total) a partir de ciertas variables: composición de las comisiones directivas, períodos de elección de autoridades, número de socios, cuántos están habilitados para votar y cuántos efectivamente votan, cantidad y tipo de deportes amateurs. La información acerca de tales datos se obtuvo a través de la consulta de fuentes como los sitios webs oficiales, las agrupaciones políticas de los clubes y la prensa nacional y provincial. ${ }^{2}$ Para los otros casos de América Latina, revisamos la literatura sobre el tema así como también realizamos consultas a investigadores dedicados a este campo de investigación. ${ }^{3}$

Los apartados que componen este artículo se refieren a las dimensiones antes mencionadas. En primer lugar, presentamos la polémica desatada entre el modelo jurídico empresarial impulsado desde la década de los noventa del

\footnotetext{
${ }^{2}$ Proyecto de investigación financiado por la Universidad de Buenos Aires: "Lazos de una misma trama. Política(s), trayectorias y relaciones entre dirigentes deportivos, hinchas de fútbol y políticos tradicionales".

${ }^{3}$ Agradezco la colaboración del Dr. Gustavo Andrada Bandeira de la Universidad Federal de Rio Grande do Sul, Porto Alegre, Brasil; Dr. Martin Curi de la Universidad Federal Fluminense, Nitéroi, Brasil; Mg. Irlan Simões Santos de la Universidad del Estado de Rio de Janeiro, Brasil; el investigador Rodrigo Soto Lagos de la Universidad Andrés Bello, Chile; así como también a Diego Murzi, Gustavo Mehl, Fernando Olivera Medina y Fernando Álvarez.
} 
siglo pasado y el modelo centenario asociacionista que signó la trayectoria de las instituciones deportivas por varias décadas. La segunda parte del trabajo da cuenta de las innovaciones que se fueron incorporando en los clubes como resultados de la mercantilización del fútbol. Finalmente, el tercer punto sitúa la mirada en las prácticas y representaciones de socios e hinchas para mostrar cómo estos se manifiestan frente a las transformaciones estructurales y las decisiones tomadas desde los sectores de poder.

\section{Formato jurídico de los clubes: del asociacionismo al modelo empresarial} ¿Por qué discutir acerca del modelo legal de las entidades deportivas que tienen fútbol profesional? Porque el debate permite sacar a la luz una serie de dimensiones que están siendo modificadas en los clubes por el proceso económico de escala mundial. Esto es, dimensiones de la sociedad actual tales como la salud, la educación, los servicios públicos, las instituciones de la sociedad civil son afectadas a diario por el avance del capitalismo. Los clubes de fútbol no son la excepción.

Un caso emblemático de incorporación de capital económico ajeno a los clubes ha sido el de Chile. La transformación de los clubes en empresas se legalizó el 5 de mayo de 2005, cuando el Congreso Nacional promulgó la ley n. ${ }^{\circ} 20.019$ para regular el funcionamiento de las Sociedades Anónimas Deportivas Profesionales (SADP). La discusión y presentación del proyecto de ley, que se inició el 23 de julio de 2002, contó con el apoyo de distintas personalidades del mundo empresarial y de todo el sector de la clase política -una figura sobresaliente fue Sebastián Piñera-. ${ }^{4}$ Desde entonces,

Los clubes deportivos que en su mayoría funcionaban como corporaciones sin fines de lucro fueron presionados desde distintos frentes para transformarse en sociedades anónimas, con un nuevo marco regulatorio y nuevas condiciones que han transformado la propia manera de entender y hacer el fútbol. (Muñoz y González, 2015:3)

La propuesta de convertir los clubes en empresas cobró legitimidad en el marco del endeudamiento millonario que varias instituciones tenían en su haber. La quiebra del Club Social y Deportivo Colo-Colo en 2002, seguida dos años más tarde por el Club Universidad de Chile, sirvió para poner en discusión la viabilidad de la lógica asociativa. Los hacedores de la privatización sostenían que era prioritario "modernizar" la gestión de los clubes para dotar de mayor transparencia sus administraciones (Moreira, Soto Lagos y Vergara Costela, 2013).

\footnotetext{
${ }^{4}$ Actual presidente de Chile desde diciembre de 2017. Entre 2010-2014, ejerció su primer mandato.
} 
La institucionalización de las sociedades anónimas deportivas produjo, al menos, dos resultados. En primer lugar, el rol social y el fomento de los deportes amateurs, aspectos que habían caracterizado a las instituciones chilenas desde sus orígenes, resultaron claramente afectados debido a que la nueva ley no reglamentó las obligaciones que las empresas debían seguir al respecto.

A diferencia de hoy, las antiguas corporaciones sin fines de lucro no se enfocaban solamente en un deporte [...] Colo-Colo, además de ser el equipo de fútbol más popular del país, a lo largo de su historia contó también con ramas de deportes como ajedrez, atletismo, automovilismo, boxeo, bicicross, ciclismo, equitación, esgrima, hockey patín, natación, patinaje artístico, polo, rugby, squash, tenis de mesa y voleibol.5 (Muñoz y González, 2015: 12)

Como ha sucedido también en Argentina, las corporaciones sin fines de lucro de Chile prestaban servicios a la comunidad a través de acciones concretas, como la asistencia de médicos y dentistas a los socios e hijos de los socios de manera totalmente gratuita (Muñoz y González, 2015). Brindar una ayuda a la comunidad e invertir en el desarrollo de deportes no profesionales, significaba para las empresas bajar la rentabilidad. ${ }^{6}$

La segunda consecuencia fue la clausura definitiva del acceso de los socios a la toma de decisiones en sus respectivos clubes. Con el nuevo formato jurídico se anularon los mecanismos de elección, representación y participación resultantes de los procesos políticos internos. Por otra parte, como la nueva normativa siguió el modelo inglés, se habilitó el ingreso de capitales privados (tanto empresas como personas) al negocio del fútbol mediante la compra de acciones sin límite porcentual (ibidem). La antítesis del modelo inglés es la Bundesliga alemana, donde los socios mantienen el control del " $50+1$ " por ciento de las acciones y los votos en la toma de decisiones del club S.A.

Por otro lado, con el advenimiento de las SADP la mayor parte de los clubes no tiene vinculación directa con sus socios. Hoy en casi la totalidad de los clubes profesionales de fútbol, el socio sólo tiene derecho a descuento en la compra de entradas o merchandising del club. El actual socio no tiene derecho a voto en las reuniones de directorio o tampoco a utilizar las instalaciones de la institución (salvo en el caso de CSD Colo-Colo).

\footnotetext{
${ }^{5}$ Del plantel original de ramas deportivas sólo se mantuvo el patín, que fue financiado por los interesados.

${ }^{6}$ En países como Argentina, donde no se ha legislado a favor de la formación de las sociedades anónimas, los socios defensores del modelo asociacionista argumentan que el resultado de una futura privatización sería la eliminación de las disciplinas amateurs.
} 
Hoy, en la mayoría de los casos, los clubes de fútbol son manejados por personas completamente ajenas al mundo de este deporte. (Muñoz y González, 2015: 53)

Desde hace veinte años, los clubes latinoamericanos han tratado de emular las transformaciones que se produjeron en las ligas más importantes de Europa en pleno avance del neoliberalismo, no sólo en relación con el cambio legal ${ }^{7}$ sino también con la modernización de sus administraciones (veremos esto en el siguiente acápite). En determinados países como Chile, Uruguay, Brasil y Perú, los legisladores votaron leyes que favorecieron el desembarco de capitales económicos para constituir sociedades anónimas deportivas, las cuales conviven, según los casos, con las asociaciones civiles. Por su parte, en Argentina, donde los clubes siguen siendo asociaciones civiles y no existe una legislación que regule la transformación de éstas en sociedades anónimas, el tema está presente en la agenda de los medios de comunicación y de un sector de la política debido a la declaración pública a favor de la privatización efectuada por el actual Presidente de la Nación, Mauricio Macri. ${ }^{8}$ El primer intento para realizar este cambio en el fútbol argentino se dio a fines de los años noventa del siglo Xx y, precisamente, el impulsor de la idea fue el propio Macri cuando desempeñaba su cargo como presidente del Club Atlético Boca Juniors (1995-2007).

Frydenberg (1997) señala un aspecto que ha caracterizado a los clubes de fútbol en Argentina. Desde sus orígenes, tales instituciones funcionaron como centros de reunión donde los socios debatían en conjunto problemas prácticos vinculados al nombre del club, el color de la camiseta, el campo de juego, el cobro de la cuota social o la formación de los equipos. Este carácter colectivo del funcionamiento de los clubes se sumó a la corriente asociativa de las primeras décadas del siglo Xx, que englobaba también a las sociedades de fomento barriales, las bibliotecas populares, los sindicatos de los trabajadores o las sociedades de socorros mutuos de los inmigrantes. Transcurridas varias décadas, el asociacionismo es un modelo que hoy en día continúa valorándose, siguiendo a Putman (1999), por su potencial para el intercambio de ideas disímiles o afines, la convivencia de ciudadanos de diferentes orígenes u opiniones, el desarrollo de virtudes cívicas, el entrenamiento en la vida

\footnotetext{
${ }_{7}^{7}$ La experiencia italiana de conversión de clubes en empresas funcionó como referente de los cambios que se sucedieron en los marcos regulatorios de otros países. El 23 de marzo de 1981, la legislación italiana dio libertad a los clubes de fútbol para reemplazar el asociacionismo por el modelo jurídico de la sociedad comercial. Esto sucedió en Francia en 1984 y en España en 1990. Todos los casos se inspiraron en el país precursor en la materia, Inglaterra, cuyos clubes hacía tiempo que estaban en manos de compañías privadas.

${ }^{8}$ Integrante de una familia multimillonaria, Macri asumió el 10 de diciembre de 2015 haciendo girar el rumbo del gobierno hacia una posición política de derecha.
} 
social y democrática, y el despliegue de reglas que deben ser respetadas por los participantes a la manera de un sistema político.

Los clubes de fútbol funcionan con un estatuto social donde se detallan las maneras de llevar a cabo los eventos formales tales como la elección de los dirigentes (quiénes votan, cómo deben hacerlo, cuáles son los requisitos para presentarse como candidatos o electores), la constitución de las asambleas de socios o las reuniones de la comisión directiva. Meses antes de la elección, la campaña electoral de los candidatos hace que la política interna adquiera mayor visibilidad (los políticos aparecen en los medios de comunicación, usan carteles de promoción en el espacio público, organizan reuniones). Los socios participan en distintos eventos políticos y/o acuden a la sede social de sus clubes cada dos, tres o cuatro años para elegir a los dirigentes (presidente, vicepresidentes, secretarios, vocales). El asociacionismo condiciona favorablemente el despliegue de prácticas políticas en las entidades con fútbol profesional.

También es oportuno destacar que si bien las elecciones son eventos que convocan a socios que quieren intervenir en la vida institucional como votantes y/o dirigentes, en rigor no todos acceden a las posiciones reconocidas y encumbradas del poder político. Por lo general, las personas que ocupan puestos de dirección gozan de un tiempo libre dado por la profesión o el trabajo que realizan. El rol económico de los dirigentes incluye las profesionales liberales como la abogacía, la administración de empresas o la economía, así como también la actividad comercial y empresarial. La desigual distribución del tiempo libre introduce una concentración de cargos administrativos en provecho de aquellos que disponen del tiempo necesario para cumplir las funciones de manera gratuita (Bourdieu, 2007). Algunos autores han destacado que como los dirigentes realizan su trabajo sin cobrar remuneración, se produce la coexistencia de dos éticas opuestas: un fútbol profesional administrado por dirigentes amateurs (Cruz, 2005).

En Brasil, la ley n. ${ }^{\circ}$ 9.615, conocida como Ley Pelé, sancionada el 24 de marzo de 1998, dio libertad a los clubes para que se convirtieran en S.A. No obstante, la mayoría de ellos continuaron y continúan hasta el día de hoy con el modelo jurídico de la asociación civil. Lo notable de este caso, en comparación con el argentino, es que el sistema político de elección de los dirigentes es restrictivo para la mayoría de los socios. La masa de socios plenos, que son los habilitados para votar, es reducida debido al costo de la cuota social. La participación en las elecciones queda a cargo de un pequeño y selecto grupo de personas que década tras década reproducen un modelo elitista y aristocrático. En este marco, como explica Irlan Simões Santos, hacia la década de los noventa del siglo pasado, los dirigentes del fútbol brasileño 
inventaron la figura del "socio abonado", es decir, el socio que paga para asistir a los partidos. Dicha construcción se dio pensando en los servicios que el estadio podía ofrecer al ahora socio convertido en "consumidor". A diferencia de Argentina, los "socios abonados" no tienen derecho a votar. Sin embargo, el fútbol brasileño cuenta con algunas excepciones:

En el año 2000, en una acción audaz, el Sport Club Internacional decide que sus socios abonados, incluso los vinculados a los planes más baratos, pasarían a tener derecho a votar para elegir al presidente y a los miembros del Consejo Deliberativo. En los años siguientes, con la creación de planes accesibles el club pasó a tener la mayor masa social del país, alcanzando los 42000 socios y realizando elecciones con casi 17000 electores. Años después, en medio de una gran crisis, el Grêmio de Foot-Ball Porto Alegrense sigue los pasos del rival, reformando sus estatutos para que los socios puedan participar en la elección del presidente y del consejo deliberativo del club. En el 2012, el club alcanzó su elección récord con la participación de más de 13000 socios (alrededor del 40\% de los socios con derecho a voto). Desde las iniciativas gauchas -notables por la cultura asociativa de la población local, que se ve reflejada en el ímpetu por asociarse al club- hasta la actualidad, la cronología de las reformas estatutarias para la democratización de los principales clubes brasileños es imprecisa. Hasta donde nuestra investigación consiguió llegar, el proceso ya abarcó clubes como el Curitiba, el Bahía, el Victoria, el Fluminense y el Atlético Paranaense, destacando la existencia de diferentes niveles de accesibilidad y capacidad deliberativa en cada una de dichas instituciones. (Santos, s. f.)

La democratización de la estructura dirigente es un objetivo que articula la organización de varias agrupaciones de hinchas como: Coletivo Democracia Corinthiana, del Sport Club Corinthians Paulista; Coletivo Democracia Santacruzense, del Santa Cruz Futebol Clube; Frente Vitória Popular, del Esporte Clube Vitória; Flamengo da Gente, del Clube de Regatas Flamengo; Movimento Clube do Povo, del ABC Futebol Clube; Revolução Tricolor, del Esporte Clube Bahia; Movimento Ocupa Palestra, del Sociedade Esportiva Palmeiras; Somos o Cruzeiro, del Cruzeiro Esporte Clube, y O Povo do Clube, del Sport Club Internacional.

Desde la década de los noventa del siglo pasado hasta la actualidad, un sector constituido por dirigentes deportivos, empresarios y políticos ha impulsado la sanción de una ley para habilitar la transformación de las asociaciones civiles deportivas en empresas, usando el argumento de la poca transparencia en la administración de las instituciones (muchas entidades han tenido y tienen deudas millonarias) y la falta de experiencia para afrontar las innovaciones del proceso "modernizador". La posición contra la perpetuidad del modelo 
asociacionista se ha basado en la idea de la eficiencia y la racionalización de las decisiones y administraciones. Veremos a continuación algunas características de dicho proceso.

\section{Mercantilización de las instituciones futbolísticas}

A través de las tecnologías de la información y comunicación, el fútbol se convirtió en "una práctica cultural dominante a escala global durante la década de los noventa" (Villena Fiengo, 2003: 257) del siglo pasado. Sin duda, gracias a la inserción de los medios de comunicación en el campo del deporte, surgió la posibilidad de la mercantilización del fútbol. Dicha incorporación fue preparando el terreno para producir un cambio en la composición de los ingresos económicos de las instituciones, que comenzaron a recaudar más dinero por los derechos cedidos para transmitir los partidos y por la publicidad (Proni y Zaia, 2007).

Cruz (2005) explica que "la gestión moderna" del fútbol en Europa se afianzó con la búsqueda de una administración empresarial y con el vuelco hacia el carácter profesional de los dirigentes, quienes estaban más orientados por la ética del lucro y por las estrategias del marketing deportivo. Proni y Zaia (2007) sugieren que en los países más ricos, donde la economía de mercado imperaba en el interior del campo deportivo, el fútbol se transformó en un producto muy valorizado, especialmente por su potencial de marketing. ${ }^{9}$ Los dirigentes, que eran profesionales y estaban preparados para desarrollar técnicas y estrategias comerciales, debían aspirar a posicionar a sus clubes en el mercado internacional con la intención de conseguir patrocinadores lucrativos y procurar el aumento de las ventas de los productos salidos de la propia cantera deportiva. Ambas instancias permitían el ingreso de dinero a las entidades futbolísticas europeas que, en muchos casos, eran sociedades comerciales. La adopción de la modalidad supeditada a las leyes del mercado global exigió que se pensara en el hincha como un cliente o un consumidor.

El proceso modernizador tuvo una serie de pilares que se sintetizan en varias dimensiones: el marketing deportivo, la instalación del club como una marca, el crecimiento de las empresas patrocinadoras, la venta de productos licenciados, la remodelación de los estadios para transformarlos en centros de conferencias y paseos turísticos.

La modernización que se desarrollaba a nivel global no sólo preparaba el terreno para las innovaciones en el campo deportivo latinoamericano,

\footnotetext{
${ }^{9}$ El marketing deportivo fue la carta de triunfo de varios de los grandes clubes europeos. Por ejemplo, el $70 \%$ de los ingresos de un equipo como el Manchester United correspondían al merchandising (Proni, 2000).
} 
sino que parecía exigirlas a los equipos grandes y con posibilidades de insertarse en el concierto de clubes en un mercado de alcance internacional. Si, como dice King (2009), el fútbol europeo consistía en un único mercado dominado por los grandes clubes que se ubican en puntos clave de una red que trascendía las fronteras nacionales (en redes transnacionales integradas verticalmente), los clubes mejor posicionados en el campo regional pretendían también competir, aunque fuese periféricamente, en el mercado global (de jugadores, objetos de la marca del club, patrocinadores). Ciertas instituciones futbolísticas tuvieron mejores condiciones para escalar porque disponían de un crédito logrado en base a triunfos ganados y acumulados a lo largo de su historia. Además, los clubes populares ${ }^{10}$ gozaban de un crédito basado en el elevado número de hinchas, percibidos como futuros consumidores de los productos de los patrocinadores.

Toledo (2002) explica qué criterios más racionales y universalizados se fueron imponiendo en los clubes de fútbol brasileños para formar un nuevo tipo de élite, reclutada en ámbitos diferentes a las vías tradicionales impuestas por las sucesiones familiares y la circulación restringida de cargos y derechos entre los sectores de socios antiguos o vitalicios. Los nuevos directivos eran egresados de institutos de formación en gestión y administración. Era una élite creada en un medio universitario. Los dirigentes egresados de tales centros de formación dominaban la gramática empresarial, los fundamentos de la administración, los procesos racionales y optimizados del marketing deportivo. Los nuevos políticos empresarios se fueron mezclando con los dirigentes que nacieron dentro de los clubes, integrados en ellos mediante redes de relaciones personales y de afinidades establecidas localmente (Toledo, 2002).

En Argentina, la nueva era coincidió con la apertura y llegada de dirigentes con breves trayectorias en el campo futbolístico. Los individuos que comenzaron a integrar las comisiones directivas de los clubes locales conocían las estrategias y las reglas del mercado porque participaban activamente en el mundo de los negocios. La relación entre el área de las ocupaciones privadas que ellos tenían como empresarios o directivos de firmas comerciales y el léxico empresarial que utilizaban era notoria (Moreira e Hijós, 2013). En este período se gestó la contratación de especialistas en marketing deportivo y administración económico-financiera. "Los técnicos" eran los encargados de implementar criterios más racionales y universalizados (Toledo, 2002) para organizar el club y la batería de oportunidades que se abría en torno al fútbol

${ }^{10}$ La división entre equipos "grandes y chicos" es compatible con las representaciones de los medios de comunicación masivos que, basados en la lógica mercantil, realizan coberturas más amplias de los equipos del primer bloque, que son aquellos que generan mayores audiencias. 
televisado. La valoración positiva de "lo técnico" se manifestó en un aspecto inédito: algunos especialistas contratados, que cumplían funciones centrales (gerente general, gerente administrativo, gerente de marketing y gestión comercial) eran simpatizantes de otros clubes. Antiguamente, cuando las funciones administrativas de los clubes no eran tan especializadas, los cargos se dividían entre los dirigentes elegidos por $-\mathrm{y}$ entre- los socios.

Un criterio racional del proceso modernizador en Argentina fue la creación y la comercialización de "la marca" de los clubes. Este carácter innovador tuvo lugar en la entidad con mayor número de hinchas del país: el Club Atlético Boca Juniors. El proceso modernizador se caracterizó por la aplicación de técnicas que permitieron maximizar la utilidad del fútbol. Las medidas impulsadas a partir del primer gobierno de Mauricio Macri llevaron al club a crecer económicamente y a convertirse en una de las marcas corporativas de mayor facturación. Hijós (2014) explica que el plan de reestructuración de la imagen de la institución fue un ejemplo de lo que se denomina sport management que, sintéticamente, se refiere a la aplicación de técnicas y estrategias propias de las compañías modernas. Así, su reorganización incluyó algunos elementos de competencia empresarial: la creación de una identidad para distinguirse como una institución diferente; la formación de una imagen a través de la cual el club sería visto y reconocido a nivel mundial, y la contratación de un coaching gerencial que en esta entidad se tradujo en la incorporación de un líder con la suficiente empatía para resolver los problemas internos del equipo profesional de fútbol.

El estudio que Cruz (2005) realizó sobre las alteraciones estructurales ocurridas en los estadios brasileños, arrojó resultados sobre las repercusiones que éstas tuvieron entre los asistentes y la forma peculiar que adquirió el espectáculo futbolístico en dicho país. Las reformas arquitectónicas significaron la implantación del fútbol brasileño en un formato de intercambios comerciales capitalistas. El nuevo modelo signado por la gestión empresarial, fue elaborado por las autoridades de los clubes como una solución para superar la crisis económica y estructural que atravesaban la mayor parte de las instituciones. En este marco, los nuevos profesionales percibieron que uno de los medios más eficientes para convertir un club en una entidad financieramente independiente-que ganara fondos provenientes de la propaganda y el marketing-era precisamente la construcción de "arenas ultramodernas polivalentes". Estos recintos facilitarían la entrada de divisas en el club, no sólo a través de la venta directa de entradas los días de partido o de abonos por temporada, sino también por la explotación del estadio. Con las reformas, éste podía tener un uso diversificado como escenario de espectáculos y convenciones, y como espacio para la explotación comercial, tanto en el interior como en el exterior, 
con lugares destinados a estacionamientos, tiendas, centros comerciales, restaurantes y museos (Cruz, 2005).

El Club Atlético Paranaense (CAP) del estado de Paraná, ubicado en el sudoeste de Brasil, fue considerado un ejemplo de modernización. Sus dirigentes buscaron la acumulación de una serie de factores atrayentes para realizar negocios rentables y aumentar el volumen de su capital económico y simbólico. El Arena da Baixada, de 1999, fue la primera tentativa brasileña para adecuar los estadios a "la modernidad". La estrategia consistió en renovar el patrimonio del club para elevar la posición del mismo en el campo futbolístico. La intención de los dirigentes era implantar al CAP en el primer plano del escenario futbolístico brasileño a fin de llamar la atención de futuros inversores. Según Mosko (2007), la demolición del antiguo estadio, la construcción de uno totalmente renovado en base a los modelos europeos y la edificación del centro de entrenamiento más moderno del país, ponían de manifiesto que el objetivo de las autoridades era obtener un capital simbólico que elevara la posición de la institución en la lucha contra otras entidades. Esta institución constituyó el precedente donde la implantación de un proceso modernizador dio excelentes resultados. Después de la inversión edilicia y de la formación de un plantel competitivo, el CAP consiguió sus primeros campeonatos nacionales a partir de 2005. Tal como esperaban las autoridades, este hecho, desde luego, incrementó el valor de su marca e imagen en el concierto de los otros clubes del país.

En Argentina, el pionero fue el Club Boca Juniors. La modernización no implicó la construcción de un nuevo estadio sino la remodelación del existente. Como cuenta Hijós (2014), el emprendimiento contó con nuevas butacas, estacionamiento, rampas de acceso, campo de juego rodeado de vidrio con laminado de seguridad, doble iluminación, sistema de audio y video, y un palco presidencial de acuerdo con las normativas de la FIFA. Las tareas se concentraron en el acondicionamiento de todos los sectores del estadio y, especialmente, en la remodelación de un tramo en donde se demolieron los antiguos palcos, reemplazados luego por una pequeña tribuna sobre la cual se construyeron 200 plateas preferenciales y 32 palcos VIP cubiertos y alfombrados, con espacios para 6 personas, equipados con minibar, aire acondicionado, baño privado y televisión. La incorporación de estos servicios repercutió en el aumento del valor de las entradas y los abonos para ver los partidos. La reforma del estadio implicó también la creación de un espacio dedicado a la historia de la institución. Teniendo como referencia los clubes europeos, los dirigentes crearon el Museo de la Pasión Boquense, que cautivó la atención no solo de los hinchas sino también de los turistas que se acercaban al lugar como un punto de referencia 
en sus recorridos por Buenos Aires -actualmente, el museo es administrado por un consorcio de empresas comerciales- (Moreira, 2010; Hijós, 2014). ${ }^{11}$

\section{Participación social y política de socios e hinchas}

Las respuestas frente a las medidas destinadas a modernizar los clubes y/o a convertirlos en empresas han sido heterogéneas. La construcción o remodelación de los estadios es un proyecto que, por lo general, genera dudas y discusión. Ciertas reformas pueden entrar en conflicto con la forma de actuar de socios e hinchas ${ }^{12}$ que ven los estadios como lugares propios que albergan en su interior múltiples significados. Son espacios que, década tras década, han sedimentado experiencias individuales y colectivas, tradiciones de toda la vida, recuerdos familiares y vivencias afectivas. ${ }^{13}$ Por todo esto, el estadio no es sólo un patrimonio material, sino también un patrimonio intangible.

Algunos proyectos e innovaciones edilicias entran en contradicción con las prácticas y representaciones habituales de socios e hinchas. Frente al anuncio del actual presidente del Club Atlético Boca Juniors de construir un nuevo estadio de fútbol siguiendo los patrones europeos, los hinchas planificaron una serie de manifestaciones que dieron en llamar "banderazo". Esto es la reunión en un espacio público donde hinchas y socios usan las clásicas banderas con los colores del club, para protestar a partir de consignas y cantos contras las decisiones tomadas desde el poder. ${ }^{14}$ Los dirigentes anunciaron los detalles del emprendimiento: la construcción de un recinto de dos anillos con una capacidad para 75000 u 80000 personas, con mayoría de butacas y un reducido espacio para las tribunas populares (Hijós, 2017). La protesta de los detractores se originó no sólo por el abandono -y posible demolición- de la antigua "bombonera", sino también por la posible exclusión del espectáculo de las clases medias y populares.

En Brasil, la construcción de las arenas polivalentes, realizadas con una inversión muy elevada, condujo a la selección de un nuevo público en detrimento del público habitual constituido por las clases populares (Santos, 2016). Este proceso desató la organización de los hinchas que expresaron públicamente una serie de demandas contra el avance del mercado y la "elitización" de los estadios. En este contexto, por ejemplo, el grupo Dissidenti de la Sociedade

\footnotetext{
${ }^{11}$ En 2009, el Club Atlético River Plate inauguró su propio museo.

${ }^{12}$ La distinción entre socios e hinchas se debe a que muchos hinchas no son socios del club. Además, en Argentina hay personas que se asocian al club para practicar algún deporte y no son hinchas. No nos referimos a éstos últimos en el presente análisis.

${ }^{13}$ En Argentina, compartir un estadio con otro equipo, como sucede en Italia o Brasil, es un hecho que genera resistencia. Cada club tiene su estadio.

14 "Hinchas de Boca reclamaron en contra de un nuevo estadio", Diario Popular, 25 de mayo de 2016. Consultado el 15.03.2018, en https://www.diariopopular.com.ar/futbol/ hinchas-boca-reclamaron-contra-un-nuevo-estadio-n258634.
} 
Esportiva Palmeiras de São Paulo es un sector que busca consensuar entre sus integrantes la lucha por ampliar el acceso a las tribunas. Así mismo, en el plan organizativo figura la búsqueda de una mayor participación de los socios en una institución que se caracteriza por ser políticamente restringida (Santos, 2016).

Sobre dicho proceso de exclusión, Bandeira sugiere:

Tal vez, la principal controversia en relación con los nuevos estadios brasileños fue, justamente, su proceso de elitización. Casi siempre las mejoras se tradujeron en un aumento de los costos y del precio de las entradas, que terminó alejando a los aficionados con menor poder adquisitivo. Aunque en alguna medida pudo haber sido catalizado por el Mundial, este proceso no es nuevo. Durante la primera década de este siglo, diferentes estadios ya estaban sustituyendo sus sectores populares con palcos, en un proceso que podría ser entendido como elitización de los estadios. (Bandeira, 2017: 85)

A partir de la segunda década de este siglo es posible observar, a través de una serie de dimensiones, una mayor participación de los hinchas y socios argentinos en sus instituciones, el aumento de las masas societarias de muchos clubes y la creación de nuevos ámbitos institucionales para la participación en distintas comisiones y subcomisiones, que organizan diferentes actividades alrededor de los partidos de fútbol o de otro tipo en nombre del club ("la subcomisión del hincha" que prepara el colorido en la tribuna, por dar un ejemplo).

En ocasiones, las movilizaciones, festejos o reclamaciones de los hinchas y socios organizados se vuelven multitudinarias y exponencialmente visibles en el tejido urbano. Miles de hinchas y socios del Club San Lorenzo de Almagro se movilizaron a la Plaza de Mayo, en el centro de la Ciudad de Buenos Aires, reclamando una ley de restitución histórica para "regresar a Boedo" (pretendiendo reubicar nuevamente en dicho barrio porteño su estadio, expropiado por la última dictadura militar en Argentina). Previamente habían realizado marchas a la Legislatura de la ciudad de Buenos Aires ${ }^{15}$ (Daskal y Moreira, 2017). De igual manera, los hinchas del Independiente, ante la ausencia de un festejo programado por las autoridades del club, planificaron una caravana a pie y en vehículos por sus cien años de historia. El festejo convocó a 100000 personas que transitaron por las calles de la ciudad vistiendo camisetas y flameando banderas en honor al centenario del Independiente. Esta participación de socios e hinchas puede involucrar al Estado cuando

15 "Una multitud para reclamar el histórico regreso a Boedo", Clarín, 8 de marzo de 2012. Consultado el 15.03.2018, en https://www.clarin.com/deportes/impactante-hinchas-san-lorenzoboedo_0_BkP7vKUhPXe.html. 
se trata de obtener, defender o recuperar terrenos para los clubes. Lo mismo sucede con los emprendimientos solidarios: el Club Atlético Atlanta organizó un centro cultural y una orquesta sinfónica para niños de la calle. ${ }^{16}$ En todos los casos y bajo situaciones diversas aunque similares, se observa el interés por ampliar o mantener espacios del club y reivindicar su identidad barrial y su rol como espacio de contención social.

La mayor participación de los socios también se observa en el momento de las elecciones. En 2009 votaron en el River Plate más de 14000 socios, cuando cuatro años atrás lo habían hecho 7 486, y cuatro años después, en 2013, votaron 18 364. En el Boca Juniors, en 2011, una elección con poco más de 24000 votantes constituyó un récord para la institución y también aumentó la cantidad en 2015. Lo mismo ocurrió con el Club Atlético Independiente, donde votaron masivamente 11685 socios a finales del mismo año. En la misma época, en el Argentinos Juniors, un club de menor envergadura, se daba una participación histórica de más de 2100 socios votantes -casi el 50\% de los habilitados para hacerlo-. (Daskal y Moreira, 2017)

En este contexto, la declaración pública de un sector de la política y de los dirigentes de convertir a los clubes en sociedades anónimas, produjo un hecho inédito en Argentina: la reunión de hinchas de distintos equipos en un único frente, fundado en noviembre de 2016. ${ }^{17}$ Éste grupo, denominado "Coordinadora de hinchas", plantea entre sus objetivos: "lograr una mayor implicación de los socios", "combatir por conservar el carácter popular de las instituciones que no son sólo clubes de fútbol profesional" y "denunciar los abusos de las corporaciones pasando por encima de los aficionados". Los hinchas incluyeron otros puntos para discutir: la defensa de los deportes amateurs y las actividades sociales, llamar la atención sobre los problemas de género y el rol de las mujeres en el deporte, la represión policial en los estadios y los precios abusivos de las entradas. ${ }^{18}$

Para los integrantes de la Coordinadora:

Esta tendencia privatizadora y el lobby empresarial nunca dejaron de ser un peligro para nuestros clubes. Gerenciamientos encubiertos que se mantuvieron e incluso iniciativas del poder político que van a contramano del fortalecimiento del arraigo

\footnotetext{
16 "Vamos a cantar los 40", Club Atlético Atlanta, 7 de julio de 2017. Consultado el 15.03.2018, en http://www.caatlanta.com.ar/archives/cantar-los-40.

17 "Lo que está faltando es la voz de los hinchas más allá del club y de la camiseta", Tiempo Argentino, 23 de diciembre de 2016. Consultado el 15.03.2018, en https://www.tiempoar.com.ar/articulo/ view/63393/lo-que-esta-faltando-es-la-voz-de-los-hinchas-ma-s-alla-del-club-y-de-la-camiseta. ${ }_{18} \mathrm{El}$ antecedente directo de este tipo de organización fue la formación en 2001 del Foro Social del Deporte, constituido por dirigentes y socios de diferentes clubes para defender las asociaciones civiles deportivas.
} 
barrial y el aspecto social de los clubes, como la construcción de estadios mal llamados únicos sin identidad, sin alma $[\ldots]^{19}$

La organización surgió del intercambio de experiencias entre diferentes agrupaciones de cuatro o cinco clubes, que coincidían en la lucha contra las sociedades anónimas deportivas (SAD). Socios e hinchas tienen la intención de seguir una agenda de reuniones y trabajo con diferentes dirigentes políticos y deportivos para que establezcan una posición firme contra la posible presentación de una ley de las SAD. Entre sus objetivos está la búsqueda de firmas de todos los sectores de los clubes, a la vez que charlas para concientizar sobre la necesidad de mantener el formato tradicional de los clubes como asociaciones civiles.

Las prácticas descritas indican un sentimiento profundo y una noción extendida acerca de que el club es un patrimonio colectivo "que no se vende". Estas prácticas y representaciones se han aprendido y se han desarrollado en el marco de un formato jurídico singular: la asociación civil. Socios e hinchas, a partir de sus acciones futbolísticas, políticas, sociales y/o culturales, han incorporado día a día el sentimiento de pertenencia a un colectivo común. En el mismo sentido, Santos (2016) sugiere que en el caso de Brasil, el hecho de que los clubes continúen siendo jurídica y estatutariamente asociaciones civiles sin fines de lucro, permite una mayor intervención de socios e hinchas.

Ya vimos que las personas vinculadas a las asociaciones deportivas tienen la posibilidad de participar como candidatos a dirigentes, votantes y/o militantes de alguna de las agrupaciones políticas que disputan el poder. También mencionamos que muchos hacen uso de las instalaciones del club porque asisten a los partidos, realizan deportes amateurs o participan de alguna actividad institucional..$^{20}$ En la apropiación que hacen del espacio (sede social, estadio, terreno deportivo) (de Certeau, 1996), tales personas van creando una relación cercana con el entorno a partir de la cual tiene sentido la frase: "el club es de los socios".

Según Muñoz y González (2015), en el fútbol chileno existen agrupaciones de socios e hinchas que están buscando caminos alternativos para intentar solucionar las nuevas problemáticas surgidas desde la instauración

${ }_{19}$ Extraído del texto "Plan de Lucha \#NoaLasSAD - Coordinadora de Hinchas", leído por un representante de la agrupación en un acto público el 10 de abril de 2018, en el hotel Bauen, Ciudad de Buenos Aires, Argentina. Consultado el 21.06.2018, en http://lastimaanadiemaestro.blogspot. com/2018/04/plan-de-lucha-noalassad-coordinadora-de.html.

${ }_{20}$ Por ejemplo, el Club Gimnasia y Esgrima de La Plata ofrece baloncesto, hockey, patín, musculación, vóleibol, tenis, artes marciales, atletismo, esgrima, gimnasia e iniciación deportiva. Además, y esto se extiende a otras entidades futbolísticas, también cuenta con niveles de enseñanza formal (jardín de infancia, primaria y secundaria). 
de las sociedades anónimas deportivas. El caso de Chile se diferencia del de Argentina y Brasil (más allá de las distancias entre ambos) por la ausencia de los mecanismos de elección, representación y participación que resultan de los procesos políticos internos de la asociación. No obstante, más allá de la clausura del sistema democrático y político en Chile, en clubes como el Santiago Wanderers y el Colo-Colo, la participación y la organización de los socios cobra visibilidad fuera de las instituciones en función de una serie de reclamaciones. El Colo-Colo es un ejemplo en este sentido: el interés de hinchas y socios ha permitido la formación de una articulación colectiva que demanda la restitución de los derechos perdidos en torno a la administración de sus instituciones. El objetivo ha sido "conseguir que los hinchas se empoderen cada vez más en la toma de decisiones de su club” (Muñoz y González, 2015).

\section{Palabras finales}

Un propósito del trabajo ha sido mostrar los cambios estructurales que se han venido produciendo bajo el proceso global que denominamos "mercantilización” del fútbol, al tiempo que indagar sobre las respuestas que éste ha provocado en los socios e hinchas de ciertos clubes en Latinoamérica. Desde la década de los noventa del siglo pasado hasta la actualidad, un sector constituido por dirigentes deportivos, empresarios y políticos en los distintos países, ha impulsado la sanción de leyes para dar paso a la transformación de las asociaciones civiles deportivas en empresas. Las innovaciones tecnológicas, racionales y universalizadas de la transnacionalización del fútbol, que tuvieron su epicentro en Europa, provocaron modificaciones en las instituciones deportivas latinoamericanas, algunas de las cuales convirtieron su formato jurídico, y/o incorporaron nuevos aspectos en la administración, en la arquitectura de los estadios y en las maneras de imaginar el deporte profesional y las actividades amateurs. El proceso modernizador implicó reformular el significado de los clubes, que comenzaron a concebirse como empresas, y el significado de los aficionados que pasaron a ser clientes. Sin embargo, las medidas mercantiles fueron encontrando límites, contextual y situacionalmente según los casos.

En determinados países como Chile y Brasil, los legisladores votaron leyes para favorecer el desembarco de capitales económicos y constituir sociedades anónimas deportivas. Por su parte, en Argentina, donde no hay una legislación que regule la transformación de los clubes en sociedades anónimas, el tema está presente en la agenda de los medios de comunicación y de un sector de la política, debido a la posición conservadora y neoliberal del actual gobierno nacional.

Para los clubes chilenos, la consecuencia directa fue la eliminación de los deportes amateurs, de las acciones dirigidas al bien comunitario y de los 
derechos de la participación política de los socios. La mayoría de los clubes de fútbol están manejados por personas completamente ajenas al mundo de este deporte. En Brasil, la ley n. ${ }^{\circ}$ 9.615, sancionada en 1998, dio libertad para que los clubes se convirtieran en S.A. Sin embargo, la mayoría de los clubes continuaron y continúan hasta la actualidad con el modelo jurídico de la asociación civil. Lo notable es que el sistema político de elección de los dirigentes es restrictivo para la mayoría de los socios. Las elecciones quedan a cargo de un pequeño y selecto grupo de personas que son las que pueden pagar una cuota social elevada (salvando excepciones tales como el Internacional y el Gremio de Porto Alegre y demás casos enunciados en el texto). Una cuestión pendiente de investigación es que debido a la posición privilegiada de las élites que gobiernan los clubes brasileños y a la escasez de actividades deportivas amateurs que mantener económicamente, es posible que no resulte necesario convertir las instituciones en empresas.

$\mathrm{Al}$ respecto, los clubes argentinos se caracterizan por la variedad de deportes no rentables, así como también por el sistema político amplio. Los procesos de elección de autoridades permiten la participación de los afiliados en su calidad de votantes y/o candidatos a los puestos de la comisión directiva, dando lugar a una mayor democratización. No obstante, como mencionamos en el análisis, dado que el desempeño de los dirigentes es amateurs, no todos los socios pueden cumplir efectivamente dicho rol por el escaso tiempo libre disponible, resultado de su posición en la estructura económica. En los últimos años, el número de votantes en las instituciones pone de manifiesto lo importante que es la participación política para los socios; participación que también se da en los eventos sociales y culturales de su cotidianidad. Ahora bien, cabe preguntarse como hipótesis si la pervivencia del formato jurídico se debe a la incorporación y sedimentación de más de cien años de prácticas e ideas asociacionistas de los afiliados argentinos, los cuales sintetizan en el lema "el club es de los socios" su lucha contra una posible privatización.

Para las instituciones que no abandonaron la tipología legal como entidades democráticas y civiles, el disgusto de hinchas y socios no se ha dado necesariamente por la búsqueda de la rentabilidad del club en su carácter de institución social y deportiva, sino por el avasallamiento de ciertos derechos -escritos o no escritos- adquiridos históricamente (la remodelación y el uso del estadio, por ejemplo). Por otra parte, cabe destacar que las manifestaciones contra los sectores de poder se han dado no sólo en las asociaciones civiles deportivas (como en el caso de la Coordinadora de Hinchas en Argentina, para nombrar un ejemplo de unión transversal de socios de distintos clubes) sino también en los clubes de Brasil y Chile; en los clubes brasileños en pos de la ampliación del sistema político; en Chile, para volver al formato de la 
corporación. Hemos mostrados cómo hinchas y socios se unen para defender los derechos subyugados. $\mathrm{Al}$ respecto, formulamos esta pregunta por su transversalidad: ¿los hinchas y socios de los distintos países latinoamericanos, con sus peculiaridades, están pensando en la organización de un frente común contra el avance del capital?

Finalmente, con mayor o menor apertura democrática, con un formato jurídico asociacionista o como empresa, todos los casos de algún modo señalan las relaciones entre los clubes y el campo de la política profesional. Si bien no ha sido analizada la doble pertenencia de ciertos individuos que cumplen una función en algún nivel del Estado (nacional, estadual o local) y son directivos en el fútbol, este trabajo también muestra el protagonismo que tienen algunos funcionarios de los gobiernos y legisladores nacionales en pos del mantenimiento o la transformación del modelo organizativo en el fútbol profesional.

Revisado por José Morales

\section{Referencias bibliográficas}

Alabarces, Pablo (2012), "Veinte años de ciencias sociales y deporte, diez años después", in David Quitián Roldán (comp.), Estudios socioculturales del deporte. Desarrollos, tránsitos y miradas. Bogotá: Kinesis, 119-130.

Archetti, Eduardo P. (1984), Fútbol y ethos. Monografías e informes de investigación, Serie Investigaciones, 7. Buenos Aires: FLACSO - Facultad Latinoamericana de Ciencias Sociales.

Bandeira, Gustavo Andrada (2017), "Do Olímpico à Arena: elitização, racismo e heterossexismo no currículo de masculinidade dos torcedores de estádio". Tesis de Doctorado en Educación presentada en la Faculdade de Educação, Universidade Federal do Rio Grande do Sul, Rio Grande do Sul, Brasil.

Bourdieu, Pierre (2007), O poder simbólico. Rio de Janeiro: Bertrand Brasil.

Cruz, Antonio Holzmeister Oswaldo (2005), "A nova economia do futebol. Uma análise do processo de modernização de alguns estádios brasileiros”. Disertación de Maestría presentada en la Universidade Federal do Rio de Janeiro, Rio de Janeiro, Brasil.

DaMatta, Roberto (comp.) (1982), Universo do futebol: esporte e sociedade brasileira. Rio de Janeiro: Pinakotheke.

Daskal, Rodrigo; Moreira, Verónica (2017), Clubes argentinos. Debates sobre un modelo. Buenos Aires: UNSAM Edita.

De Certeau, Michel (1996), La invención de lo cotidiano I. Artes de hacer. México: Universidad Iberoamericana.

Frydenberg, Julio (1997), "Prácticas y valores en el proceso de popularización del fútbol, Buenos Aires 1900-1912”, Entrepasados - Revista de Historia, 12, 7-29. 
Hijós, Nemesia (2014), "El deporte como mercancía: un estudio sobre la dimensión económica y las múltiples lógicas en el Club Atlético Boca Juniors”. Tesis de Licenciatura presentada en la Facultad de Filosofía y Letras de la Universidad de Buenos Aires, Buenos Aires, Argentina.

Hijós, Nemesia (2017), “\#DeLaBomboneraNoNosVamos: tensiones entre los modos de festejar y resistir de un grupo de hinchas de fútbol argentino”, Esporte e Sociedade, 12(29). Consultado el 31.03.2018, en http://www.uff.br/esportesociedade/pdf/es2901.pdf. King, Anthony (2009), "Os rituais do esporte”, Estudos de Sociologia, 14(2), 17-42.

Moreira, María Verónica (2010), "La política futbolizada: los dirigentes deportivos y las redes político-territoriales en Avellaneda”. Tesis de Doctorado en Ciencias Sociales presentada en la Facultad de Ciencias Sociales, Universidad de Buenos Aires, Argentina.

Moreira, María Verónica; Hijós, Nemesia (2013), "Clubes deportivos, fútbol y mercantilización: los casos de Boca Juniors e Independiente en la Argentina”, Question, 1(37), 149-162.

Moreira, María Verónica; Soto Lagos, Rodrigo; Vergara, Carlos (2013), "Prácticas y representaciones en el fútbol: estudio comparativo de los recorridos académicos entre Chile y Argentina”, Espaço Plural, 14(29), 219-245.

Mosko, José Carlos (2007), "Futebol moderno e a busca pelo capital: o ejemplo do Clube Atlético Paranaense”, in Luiz Carlos Ribeiro (comp.), Futebol e globalização. San Pablo: Fontoura, 83-105.

Muñoz, Sebastián Eduardo Campos; González, Patricio Ernesto Durán (2015), Sociedades anónimas deportivas: el caso del fútbol social. Tesis de Licenciatura en Periodismo presentada en la Escuela de Periodismo, Instituto de la Comunicación e Imagen, Universidad de Chile, Santiago de Chile, Chile.

Proni, Marcelo Weishaupt (2000), A metamorfose do futebol. Campinas, Brasil: UNICAMP - Universidade Estadual de Campinas.

Proni, Marcelo Weishaupt; Zaia, Felipe Enrique (2007), “Gestão empresarial num mundo globalizado”, in Luiz Carlos Ribeiro (comp.), Futebol e globalização. San Pablo: Fontoura, 19-47.

Putnam, Robert (1999), "Jugar al bowling sólo: el deterioro del capital social Norteamericano”, Lecturas: Educación Física y Deportes, 5(16), 1-3.

Santos, Irlan Simões (2016), "Mercantilização do futebol e movimentos de resistência dos torcedores: histórico, abordagens e experiências brasileiras”, Esporte e Sociedade, 11(27), 1-18.

Santos, Irlan Simões (s. f.), "Democracia torcedora versus vantagens consumistas: uma análise da associação em tempos de futebol-negócio”. Versión disponibilizada por el autor.

Toledo, Luiz Henrique de (2002), Lógicas no futebol. São Paulo: Hucitec.

Villena Fiengo, Sergio (2003), “Gol-balización, identidades nacionales y fútbol”, in Pablo Alabarces (comp.), Futbologías: fútbol, identidad y violencia en América Latina. Buenos Aires: CLACSO, 257-271. 
Recibido: 19.12.2017

Aceptación comunicada: 30.05 .2018

\section{Verónica Moreira}

Instituto de Investigaciones Gino Germani, Facultad de Ciencias Sociales

Universidad de Buenos Aires

Presidente J. E. Uriburu 950, 6to piso, oficina 20, (C1114AAD) Ciudad Autónoma de Buenos Aires,

Argentina

Contacto: veromoreira175@gmail.com

\section{Football, Legal Models and Market: The Dilemma of Clubs in South America}

This paper links three dimensions articulated by the discussions on football in South America: fans, the market, and internal politics. First, the frenzied debate regarding the institutions' legal format is presented. This first section on the clubs themselves and their legal models is necessary in order to later consider the different forms of participation and organization found by the actors involved in that sphere. Since the economic and political changes occurring in football clubs are not produced in isolation, the second part of this paper addresses those measures incorporated in the sporting realm as part of a global process of commercialization. The third section focuses on how club members and fans express their discontent regarding the structural transformations and decisions taken by club management. Keywords: anonymous societies; commercialization; football; profit; South America.

\section{Football, modèles juridiques et marché: le dilemme des clubs en Amérique du Sud}

Ce travail met en rapport trois dimensions qui sont la base des débats sur le football en Amérique du Sud: supporters, marché et politique interne. En premier lieu, nous abordons le débat qui est déclenché par le format légal des institutions. Il faut passer par cette première étape sur les clubs et leurs modèles légaux pour introduire par la suite les formes de participation et d'organisation auxquelles les acteurs engagés se trouvent confrontés en la matière. Comme les modifications économiques et politiques des clubs n'ont pas lieu isolément, la seconde partie du travail se penche sur les mesures qui furent incorporées dans le domaine sportif comme partie d'un processus global de mercantilisation. La troisième partie porte sur la façon dont les associés et les supporters expriment leur mécontentement face aux modifications structurelles et aux décisions politiques prises par les dirigeants des clubs. Mots-clés: Amérique du Sud; football; mercantilisation; profit; sociétés anonymes. 